\title{
Application of traditional, integrative and complementary and alternative medicines (TICAM) as an adjunct towards control and management of Covid-19 global pandemic: Can't we integrate them suitably to provide additional benefits?
}

\begin{abstract}
Corona disease 2019 (COVID-19) caused by severe acute respiratory syndrome coronavirus 2 (SARS-CoV-2) has assumed a global pandemic status more than a year back, necessitating exploration of newer strategies for prevention and treatment. In many countries, the second wave has already struck and is being tackled with some experience gained from the first phase. With the loss of innumerable human lives so far, it is felt that the modern or conventional system of medicine alone may not be enough to tackle this colossal problem, particularly in countries with a huge population and with inadequate or limited medical infra-structural facilities like adequate number of modern life-saving devices and hospital beds. Therefore, other suitable treatment methods might be needed to supplement the existing facilities. Convincing evidence-based data collected recently from different disciplines of traditional, integrative and complementary and alternative medicines (TICAM) open up the possibility of successful integration of certain systems into the mainstream or modern medicine regimens, at least as supportive or adjunct medicines to give more benefits of amelioration to the ailing mankind. The present editorial aims at bringing such possibilities to the fore.
\end{abstract}

Keywords: Covid disease 2019, severe acute respiratory syndrome coronavirus 2, traditional, integrative and complementary and alternative medicines, chinese traditional medicines, ayurvedic medicines, homeopathic medicines, acupuncture, herbal medicines
Volume I4 Issue 3 - 202I

\author{
Anisur Rahman Khuda-Bukhsh \\ Department of Zoology, University of Kalyani, India
}

Correspondence: Anisur R. Khuda-Bukhsh, Retired Professor Emeritus of UGC, Department of Zoology, University of Kalyani, Kalyani-74I235, India, Tel+9| 3325828768, +9| 9331040032, Email prof_arkb@yahoo.co.in

Received: April 23, 2021 | Published: May II, 2021
Abbreviations: Covid-19, Covid disease 2019; SARS-CoV-2, severe acute respiratory syndrome coronavirus 2; TICAM, traditional, integrative and complementary and alternative medicines; TCM, chinese traditional medicines

\section{Introduction}

Coronavirus disease 2019 (COVID-19) caused by severe acute respiratory syndrome coronavirus 2 (SARS-CoV-2) has assumed a global pandemic status affecting and killing millions of people around the world. ${ }^{1}$ The second wave has already struck in many countries with more devastating effects. The virus is undergoing mutations rapidly and new strains with altered properties are appearing in different countries making the problem more challenging. Thus, opinions and information status are periodically changing about the virus, its mode of origin and propagation, from bat to man, man to man, and now stated to be aerial. In view of the exigency arising out of rapid spread of the disease in many countries, several candidate vaccines that showed prima facie promise in several steps of trial had to be approved rather hastily by the regulatory authorities pending further studies. Despite the fact that most of the approved vaccines are generally able to provide a reasonably good degree of protection against the virus infection, the reported side-effects of some of them have become a concern for their human use in some countries, resulting in temporary stoppage pending further scientific verification. Further, currently there is lack of information on many aspects, such as, the precise degree of efficacy of the vaccine, duration of action, or whether these vaccines would be equally efficient to combat the newly arising mutated forms (double- or triple-mutated ones), whether duly vaccinated persons can also contact or transmit the disease etc. Further, in the absence of a specific anti-viral medicine in allopathy, the doctors are handicapped and have to carry on the treatment mainly focusing on symptomatic management of the disease. So far, the result of treatment appeared to vary significantly depending on the total health condition of a person, immunity status, age, co-morbidities and the actual strain of the virus that has been involved. The patients may be asymptomatic, or may be showing only mild symptoms typical of Covid-19 disease, or showing serious respiratory syndrome leading to death, for which Covid-19 disease is so much feared.

\section{Some evidence-based research data available from the TICAM on Covid-1 9}

Efforts are nevertheless being relentlessly made from all branches of medical science, including traditional, integrative and complementary and alternative medicines (TICAM) towards potentially contributing to effective control and manage Covid-19 disease globally. ${ }^{2}$ Evidencebased research data are considered very important and essential for integrating any system into modern or conventional treatment regimens even as supportive medicines.

Some branches of the TICAM have already claimed some degree of success as reported in some published research. These 
may be either preventive or curative in action. Reports of successful treatment of Covid cases by Chinese Traditional Medicines ${ }^{3,4}$ and Ayurvedic medicines ${ }^{5,6}$ are quite encouraging. In China, Chinese traditional medicines are routinely adopted to treat many cases of Covid-19, particularly at early stages or in mild cases, preventing need for hospitalization of the majority of patients. In India, reports are accumulating that point to the efficacy of certain Ayurvedic drugs in preventing and treating Covid disease quite efficiently. Ministry of AYUSH, Government of India, in its self-care guidelines for preventive health measures and immunity-boosting with special reference to respiratory health and Covid-19 crisis (available at: https://www.ayush.gov.in/) recommends to take regularly spices like Haldi (Turmeric), Jeera (Cumin), Dhaniya (Coriander), and Lahsun (Garlic) while cooking and drinking herbal tea or Kadha added with Tulsi (Basil), Dalchini (Cinnamon), Kalimirch (Black pepper), Shunthi (Dry Ginger) and Munakka (Raisin). Along with the intake of these, the practice of Yoga under a qualified trainer has been recommended to further improve immunity and mental status of people that contribute to successful defence against the attack of the virus. ${ }^{7}$ Yoga is one such system which can get along well with other medical systems to keep human fit and agile and also thereby help to increase general immunity against various diseases.

Recently, Nugrahaet al. ${ }^{8}$ discussed possibility of successful use of some herbal agents extracted from various plants, including Echinacea, Curcuma inchona, Curcuma longa, and Curcuma xanthorrhiza, which are considered to be very useful for the treatment of COVID-19. In the Unani system of medicine, Khan and Rahman ${ }^{9}$ advocated the use of certain plants like Nigella sativa, Allium sativum, Zingiberofficinale, Artemisia absinthium, Cuscuta reflexa, Cassia fistula etc, the extracts of some of which have been known to have anti-viral and immunity building capacities. Similarly, Artemisia afra and A. annura were used successfully by South African traditional healers for prevention and treatment of Covid-19 disease which produced quite satisfactory results in many patients. In the practice of age-old Siddha system of medicine, very effective plant-derived drugs with prophylactic as well as curative antiviral properties have been used for centuries in India and some other countries. ${ }^{10}$ These are Adathodai Manapagu (derived from leaf extract of Adhatoda vasica), Kabasura Kudineer (derived from dried powder of parts of fifteen different herbslike Zingiber officinale, Piper longum, Syzygium aromaticum, Tragia involucrata, Anacyclus pyrethrum, Hygrophila auriculata, Terminalia chebula, Coleus amboinicus, Saussurea lappa, Tinospora cordifolia, Clerodendrum serratum, Andrographis paniculata, Sidaacuta, and Cyperus rotundus), Nilavembu Kudineer (a polyherbal product comprising Adhatoda paniculata, Vetiveria zizanioides, $V$. zizanioides, Santalum album, T. cucumerina, C. rotundus, Zingiber officinale, Piper nigrum, and M. cerviana ), Vajra Kandi Chenduram (this formulation is made of purified lingam, veeram, pooram, and rasa sindhuram) Thontha Sura Kudineer (consists of 10 ingredients of herbs like Z. officinale, A. paniculata, T. cordifolia, Elettaria cardamomum, Solanum xanthocarpum, T. cucumerina, Tephrosia purpurea, Mollugo cerviana, and Vitis vinifera), Visha Sura Kudineer (a polyherbal formulation from the components of Azadirachta indica, Indigofera tinctoria, Z. officinale, Hemidesmus indicus, Aristolochia bracteata, V. zizanioides, Glycyrrhiza glabra, E. cardamomum, and Santalum album) etc. Many of these plant parts are also used as spices or food supplements in India. Most of these had proven antiviral, anti-inflammatory, anti-biotic, anti-bacterial, and anti-microbial properties.

Homeopathy is an immensely popular CAM practice, both in Europe and in South East Asia and in some countries like Brazil,
Mexico and some neighbouring countries. Extensive human trial is going on to find out efficacy of a potentized homeopathic drug, Arsenicum Album 30C, as an immunity booster and its role has been demonstrated in Covid prevention by researchers and clinicians working in the ministry of AYUSH, Government of India. ${ }^{11,12}$ The authors of these publications opine that scientific evidences obtained in various epidemics clearly indicate that homoeopathy can be used both therapeutically and /or as prophylactic medicine with considerable degree of success. They further advocate that the use of medicines from approaches like genus epidemicus, nosodes etc could help in Covid-19 prevention; several other homeopathic medicines based on totality of symptoms could also play a great role in the successful treatment of Covid patients. Alongside, extensive human trial is also going on in Brazil to explore possibility of integrating homeopathy in the treatment of Covid-19. ${ }^{13}$

Similarly, the role of acupuncture, particularly in removing pain and stress during Covid-19 sufferings can be successfully taken care of by acupuncture needle pricks at strategic points. ${ }^{14,15}$ In a recent study, Garfin et al. ${ }^{16}$ demonstrated how psychological distress during Covid-19 could be successfully alleviated through mindfulness-based interventions.

\section{Conclusion}

Doctors in many medically advanced countries like USA, UK, France, Italy, Spain, Germany etc who mostly depended on conventional or modern system of medicine, with all their available resources, equipped even with various life-saving devices, could not stop hundreds of thousands of people dying from Covid-19 disease, mainly because of the lack of any specific anti-viral drug capable of killing the causal virus, SARS-CoV-2, after it manages to enter and overpower immunogenic defence of the human body. Therefore, drugs with proven prophylactic action against virus and those capable of boosting immunity level should be welcome also from other systems of medicine. While more effective vaccines capable of combating all forms of the virus are eagerly awaited, we need to consider simultaneous application of some drugs from the TICAM which are known to have considerable prophylactic as well as curative actions. For the sake of providing possible additional benefits to the suffering people, is it not sensible to try out other systems alongside, particularly in the early stage and less violent cases, to minimize or reduce the pressure on the mainstream or conventional treatment, at least with an initial approach to see if this combinational approach can restrict the number of hospitalization, and/or give additional benefits to patients destined to lead to a critical state needing ultra-care in hospitals? Thus, the needs of the hour to overcome the worldwide crisis are to: i) communicate, collaborate and cooperate with experts belonging to different disciplines of treatment with an open mind to learn about the finer nuances of different branches of medical science that could be in the interest of providing better treatment and quality of life to patients, ii) scientific discoveries should be freely shared among groups of different medical practitioners and scientists, iii) strategies must be devised to give integrative approach and proper rehabilitation and long-time care to the concerned patients and iv) to design and plan scientifically for resisting and winning over a long battle by taking the best part of different systems emerging from a joint effort, wherever needed, to eliminate the Covid-19 disease from every nation.

\section{Acknowledgments}

None. 


\section{Conflicts of interest}

Author declares there are no conflicts of interest.

\section{Funding}

None.

\section{References}

1. https://www.who.int/emergencies/diseases/novel-coronavirus-2019

2. Ng Jeremy Y. Global research trends at the intersection of coronavirus disease 2019 (COVID-19) and traditional, integrative, and complementary and alternative medicine: a bibliometric analysis. BMC Complementary Medicine and Therapies. 2020;2:353.

3. Yang Y, Islam MS, Wang J, et al. Traditional Chinese medicine in the treatment of patients infected with 2019-new coronavirus (SARS-CoV2): a review and perspective. Int J Biol Sci. 16(10):1708-1717.

4. Ren JL, Zhang AH, Wang XJ. Traditional Chinese medicine for COVID-19 treatment. Pharmacol Res. 2020;155:104743.

5. Girija PLT, Sivan N. Ayurvedic treatment of COVID-19/SARS-CoV-2: A case report. J Ayurveda Integr Med. 2020;S0975-9476(20)30042-30045.

6. Joshi JA, Puthiyedath R. Outcomes of Ayurvedic care in a COVID-19 patient with hypoxia - A Case Report. J Ayurveda Integr Med. 2020.

7. Nagendra HR. Yoga for COVID-19. Int J Yoga. 2020;13(2):87-88.

8. Nugraha RV, Ridwansyah H, Ghozali M, et al. Traditional Herbal Medicine Candidates as Complementary Treatments for COVID-19: A Review of Their Mechanisms, Pros and Cons. Evid Based Complement Alternat Med. 2020;2020:2560645.
9. Khan SH, Mahbubur Rahman AK. Prophylactic and Therapeutic Approach in Unani Medicine to Counter the COVID-19: A review. Med Clin Rev. 2020;6(6):110.

10. Sabarianandh JV, Bernaitis L, Manimekalai K. COVID-19 in Siddha Medicine: A Review. J Basic Clin Appl Health Sci. 2020;3(2):83-86.

11. Chaudhary A, Khurana A. A review on the role of Homoeopathy in epidemics with some reflections on COVID-19 (SARS-CoV-2). Indian J Res Homoeopathy. 2020;14:100-109.

12. Azis SP, Kaur H. Enabling use of Homoeopathy in India's preparedness for pandemic/epidemic situation like COVID-19. Indian $J$ Res Homoeopathy. 2020;14(2):143-151.

13. Adler UC, Adler MS, Hotta LM, et al. Homeopathy for Covid-19 in Primary Care: A structured summary of a study protocol for a randomized controlled trial. Trials. 2021;22(1):109.

14. Stephanie I Cheng. Medical Acupuncture as a Treatment for Novel COVID-19-Related Respiratory Distress: Personal Experience from a Frontline Anesthesiologist. Med Acupunct. 2021;33(1):83-85.

15. Chen $\mathrm{Y}, \mathrm{Zhu} \mathrm{C}, \mathrm{Xu} \mathrm{Z}$, et al. Acupuncture for corona virus disease 2019: A protocol for systematic review and meta-analysis. Medicine. 2020;99(40):e22231.

16. Garfin DR, Cipres AL, Reyes RM. Mindfulness-based interventions to address psychological distress during COVID-19: applications and opportunities. Int J Complement Alt Med. 2021;14(2):64-67. 